\title{
A probabilistic approach to determine design loads for collision between an offshore supply vessel and offshore installations
}

\author{
M.P. Mujeeb Ahmed ${ }^{\mathrm{a}, \mathrm{b}}$ and Jeom Kee Paik ${ }^{\mathrm{a}, \mathrm{b}, \mathrm{c}^{*}}$ \\ ${ }^{a}$ Department of Naval Architecture and Ocean Engineering, Pusan National University, Busan 46241, \\ Republic of Korea \\ ${ }^{\mathrm{b}}$ The Korea Ship and Offshore Research Institute (The Lloyd's Register Foundation Research Centre \\ of Excellence), Pusan National University, Busan 46241, Republic of Korea \\ ${ }^{c}$ Department of Mechanical Engineering, University College London, London WC1E 7JE, UK \\ ${ }^{*}$ Corresponding author. E-mail address: jeompaik@pusan.ac.kr (J.K. Paik)
}

\begin{abstract}
Offshore supply vessel (OSV) collisions have been identified as the most frequent type of collision accidents in the offshore oil / gas or wind turbine industries. Quantitative risk assessment (QRA) is an efficient method for evaluating the collision risk to an offshore installation. In-depth information on collision load parameters, such as incoming ship velocity and impact location, is considered prerequisite for determining the consequences of collisions with accuracy. Thus, the aim of this study is to provide a new probabilistic method for determining collision design loads. Each input parameter is treated by a probability density function, and a set of 50 prospective collision scenarios is generated using Latin hyper cube sampling (LHS) technique. Numerical computations of ship motions are performed to obtain collision load parameters. The probabilistic characteristics of the parameters using a goodness of fit test and an interval study are carried out, and best-fit PDFs and the exceedance curve are plotted. A case study of the proposed method is demonstrated using a hypothetical OSV and an offshore jacket structure located in a hypothetical oceanic region. The details of the computations are documented, and the findings of the study are discussed.
\end{abstract}

Keywords: Offshore supply vessel (OSV), Offshore installation, Collision, Quantitative risk assessment (QRA), Probabilistic approach, Scenario selection, Collision load parameters.

\section{Introduction}

Offshore installations require regular supplies of food, equipment, chemicals and other logistics support from the offshore supply vessel (OSV) depending on the supply requirement. While in service, these vessels pose a high collision risk to installations, either due to accidental impact during approaching or manoeuvring, or due to operational impact during transfer or berthing operations. Figure 1 shows an example of a collision between a supply vessel and an offshore installation. Operational impact is usually characterised by frequent collisions associated with minor 
consequences. Figure 2 presents the operating circumstances that supply vessels were engaged on when a collision with an installation on the United Kingdom Continental Shelf (UKCS). It can be seen that 'cargo transfer' operations dominate total collision accidents, although 'approaching installation' also marked highly, perhaps also being the precursor to cargo operations.

Among the main causes of collisions are human error, engine and equipment failure, and harsh environmental conditions, with the dynamic and unpredictable nature of weather conditions, which increase collision risk, representing the main challenge to offshore logistics operations. A retrospective of accident databases reveals that ship-offshore installation collisions happen frequently (HSE, 2000). However, they show a decreasing trend due to technological development, the enforcement of strict operational rules and regulations and improved navigator training and skills, among other factors. Despite such efforts at prevention, collisions continue to occur, with many accidents involving minor collisions going unnoticed or unreported. In addition, many ships have yet to adopt the new rules and regulations for safe maritime operations.
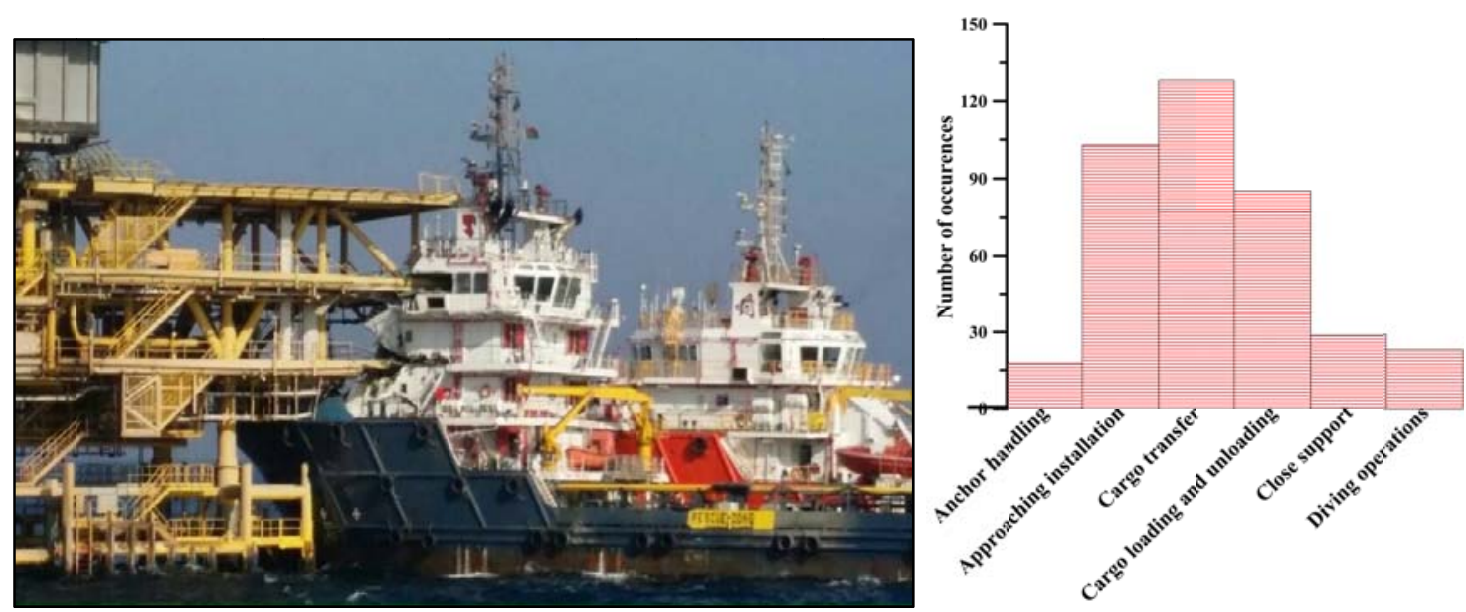

Fig. 1. Collision between tidewater supply vessel and production platform (gCaptain, 2015); Fig. 2. Collision frequency of the OSV on the UKCS based on the operating circumstances for all installations (Robson, 2003).

The design of offshore structures regarding ship collision is based on the accidental limit state (ALS), which accounts for human safety, asset losses and damage to installations or the environment (Paik, 2018; Paik and Thayamballi, 2007). The quantitative risk assessment (QRA) approach is an efficient method for evaluating collision risk and has been successfully applied for ship-ship (Youssef et al., 2016), ship-offshore wind turbine (Dai et al., 2013; Ellis et al., 2008) and ship-installation collisions (ABS, 2013; Mujeeb-Ahmed et al., 2018; Oil \& Gas UK, 2010). Figure 3 shows a general picture of the QRA framework for ship-installation collisions; the portion inside the red dotted lines indicates the main focus of the present study, i.e., the hazard identification of various collisionaffecting parameters and the probabilistic selection of collision scenarios used to analyse external collision dynamics. 


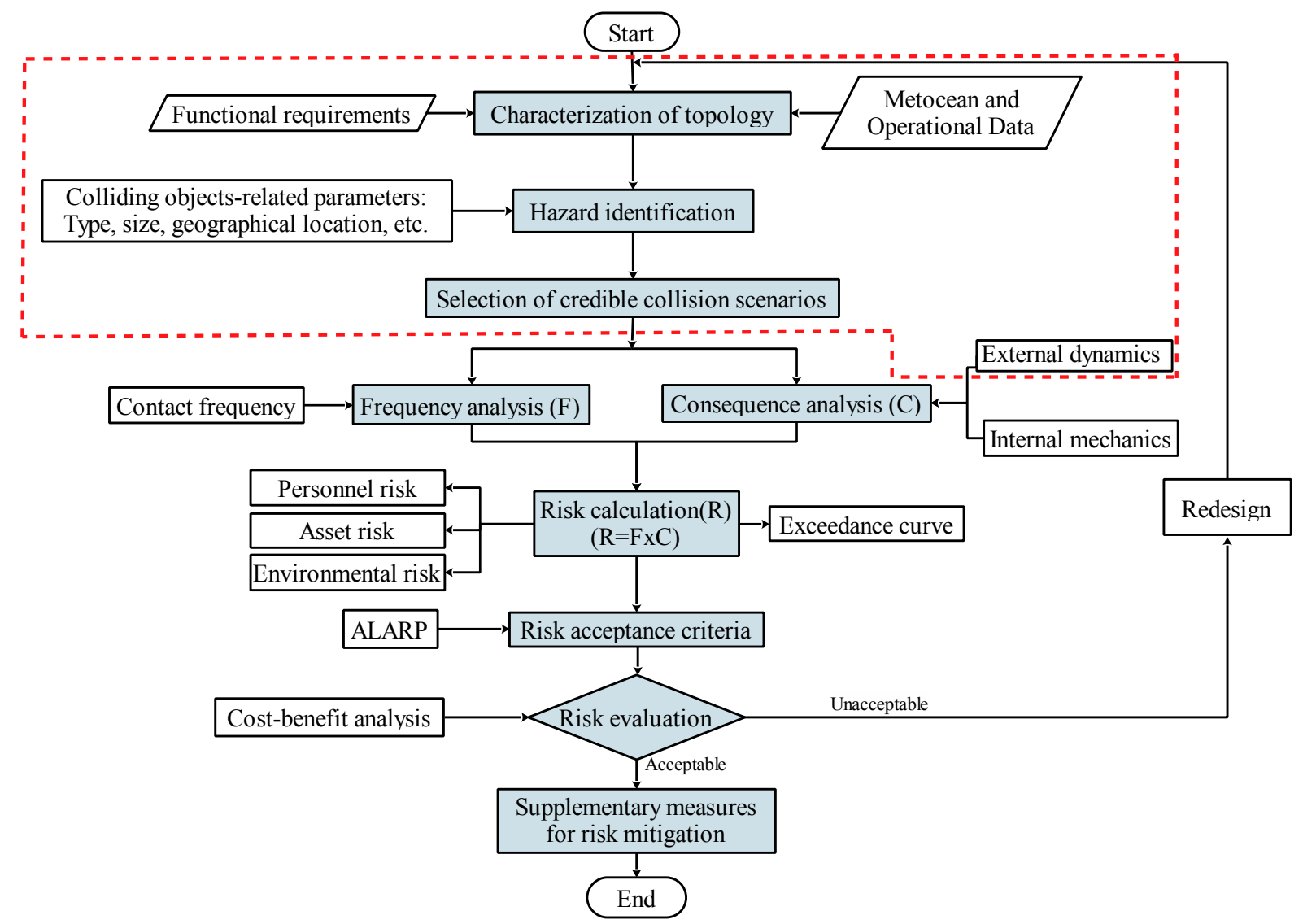

Fig. 3. The general flowchart of QRA study for collision between ship and offshore structures.

In ALS, a ship-installation collision scenario can be classified into external dynamics and internal mechanics (Pedersen and Zhang, 1999), and the coupled method estimates collision forces and structural damage with a high degree of precision (Tabri, 2012; Yu et al., 2018, 2016). While the external dynamics includes a global analysis of ship motions and a calculation of initial kinetic energy imparted to the installation, the internal mechanics involves structural strength analysis. Determining the initial kinetic energy of the supply vessel is important for calculating the energy levels in the jacket structure. During a collision only part of the kinetic energy is dissipated as strain energy for both the installation and vessel. The elastic energy accumulated in the jacket structure allows the vessel to bounce back due to the elastic property of the steel structure. Table 1 shows the accident data for some recent OSV collisions (Kvitrud, 2011).

Table 1 OSV collision accidents to the offshore installation.

\begin{tabular}{|c|c|c|c|c|}
\hline Year & Supply vessel & $\begin{array}{l}\text { Offshore } \\
\text { installation }\end{array}$ & $\begin{array}{l}\text { Velocity } \\
(\mathrm{m} / \mathrm{s})\end{array}$ & $\begin{array}{l}\text { Impact } \\
\text { location (m) }\end{array}$ \\
\hline 1996 & Smith Lloyd 8 & $\begin{array}{l}\text { Ocean Traveller } \\
\text { semisubmersible }\end{array}$ & - & - \\
\hline 2004 & Far Symphony & $\begin{array}{l}\text { West Venture } \\
\text { semisubmersible }\end{array}$ & 3.7 & $\begin{array}{l}5 \mathrm{~m} \text { above sea } \\
\text { level }\end{array}$ \\
\hline 2007 & Bourbon Surf & Grane jacket & 1 & - \\
\hline
\end{tabular}




\begin{tabular}{lllrll}
\hline 2009 & $\begin{array}{l}\text { Big Orange XVIII } \\
\text { (Well simulation) }\end{array}$ & $\begin{array}{l}\text { Ekofisk } \\
\text { jacket }\end{array}$ & 2/4-W & 4.5 & - \\
2010 & Far Grimshader & $\begin{array}{l}\text { Songa } \\
\text { semisubmersible }\end{array}$ & low & - \\
\hline
\end{tabular}

The studies on the potential consequence of collisions that use numerical or model tests depend on input loading scenarios (Zhang and Pedersen, 2017). In general, two methods are visible in the literature: deterministic and probabilistic. The deterministic method consists of selecting a few unfavourable load scenarios based on historical data, expert judgements or assumptions. Often, the chosen collision scenario represents the worst-case situation. Most researchers have followed the deterministic approach (Emami Azadi, 2011; Moulas et al., 2017), but that approach is often ineffective at generalising the collision scenarios for other installations, being based limited historical data that may be either too conservative or out of date considering the large number of parameters affecting the collision. In this approach, both past collision accidents and expert judgements form the basis for the estimation of collision design loads. Various societies and regulatory committees have recommended specific collision load parameters for design (API, 2014; DNV GL, 2017a; HSE, 2000; Lloyd's Register, 2014; NORSOK, 2004); for instance, a $2 \mathrm{~m} / \mathrm{s}$ collision velocity for a 5000 tonne displacement supply vessel (with $0.5 \mathrm{~m} / \mathrm{s}$ and 1000 tonnes for the Gulf of Mexico). The NORSOK standard (2007) defines the limits of the vertical impact zone to be $-10 \mathrm{~m}$ and $13 \mathrm{~m}$ at the lowest and highest astronomical tide, respectively. However, these limits are a function of the draft and vertical motions of the colliding vessel. Modern supply vessels are built with displacements of more than 10,000 tonnes and designed for sailing velocities greater than $2 \mathrm{~m} / \mathrm{s}$ for installations situated in deep water or ultra-deep water, considering economic transportation and navigation in rough seas. Therefore, advancement in the design of the supply vessel demands a revision of the current design values for installations (Storheim and Amdahl, 2014).

In contrast, the probabilistic approach selects prospective collision scenarios by considering each random variable in the form of a probability density function. This method has been successfully applied to various offshore and marine industry accidents (Hughes et al., 2010), for instance, ship-ship collisions (Brown, 2002; Faisal et al., 2017; Kim et al., 2015; Ko et al., 2018; Youssef et al., 2017, 2014), grounding (Youssef and Paik, 2018), sloshing (Paik et al., 2015), corrosion (Mohd et al., 2014), dropped objects (Kawsar et al., 2015), ship hull loads (Chowdhury, 2007; Garrè and Rizzuto, 2012; Ivanov, 2009; Ivanov et al., 2011) and riser loads and mooring lines (Cabrera-Miranda et al., 2017; Cabrera-Miranda and Paik, 2017). In this approach, a historical database of collision load parameters becomes the basis for quantitative risk assessment. Indeed, much research can be found on the probabilistic impact scenarios of collision damage, for ship-ship collisions, that uses historical collision data to define the collision load parameters (Brown and Chen, 2002; Goerlandt et al., 2012; Lützen, 2001; Sun et al., 2017; Tagg et al., 2002). An examination of accident databases, however, 
shows a lack of quantitative information on parameters. Although the HSE database (2001) provides a reasonable quantitative description of accidents, some load parameters, such as the collision velocity and the angle of the colliding vessel, are not to be found. Moreover, no single database provides a full quantitative description for all load parameters. Therefore, the lack of sufficient historical collision data on loads renders this probabilistic approach difficult to apply to cases of ship-installation collisions. In addition, collisions are highly uncertain and random, thus requiring cumbersome and time-consuming numerical computations to analyse all of the possible collision scenarios. Those limitations make the probabilistic approach more desirable.

In this context, the aim of this study is to develop a probabilistic model to determine the collision scenarios for ship-installation collisions. Using the probability density functions of input parameters, a set of credible collision scenarios is generated by using statistical sampling techniques. Numerical computations are performed, and the best-fit probability distribution and the exceedance curves of load parameters are plotted, which can be used to determine the design collision load.

\section{Framework of the proposed procedure}

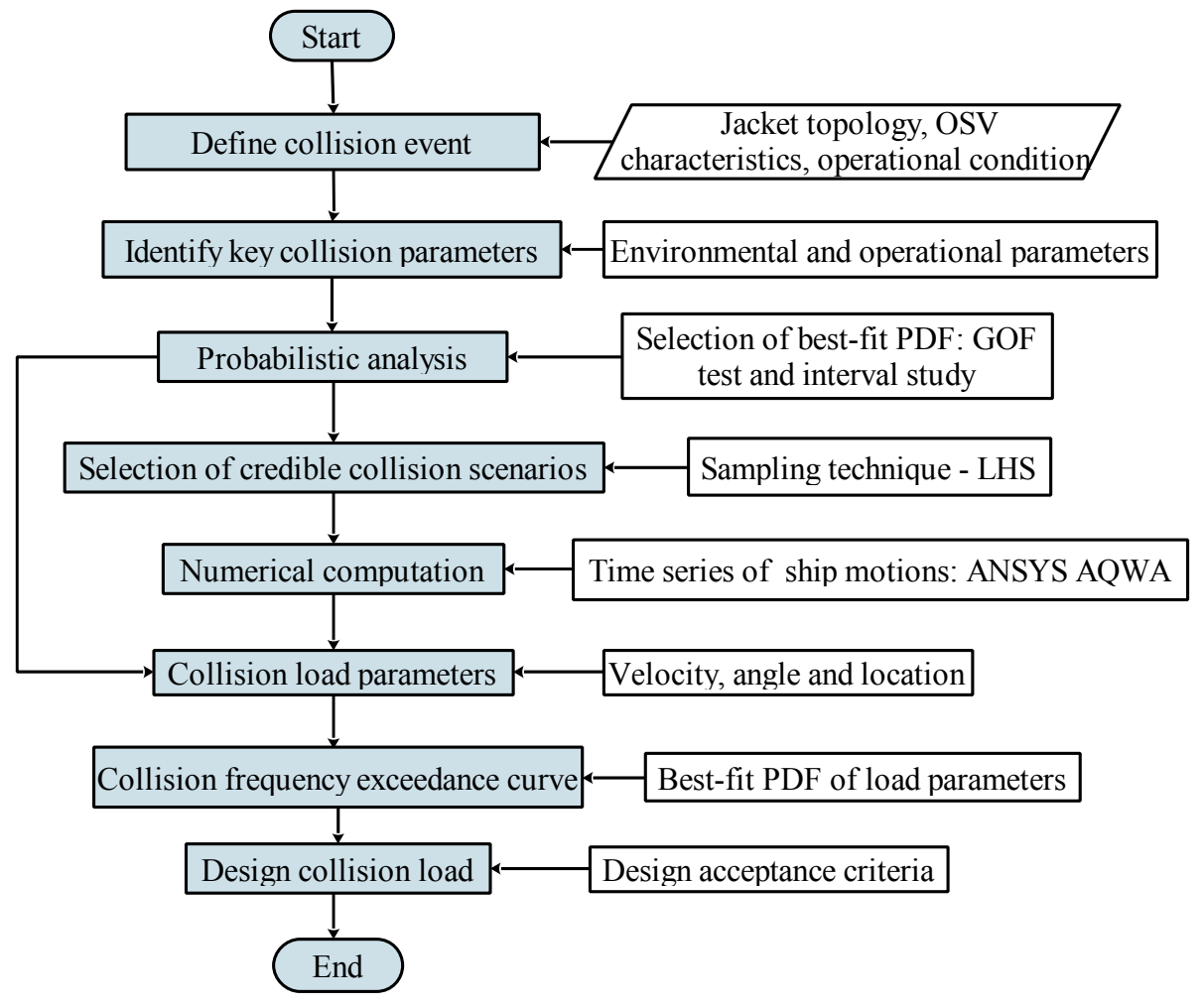

Fig. 4. Procedure for the probabilistic estimation of design collision load

Figure 4 presents a procedure of the probabilistic assessment of the collision design load followed in this study. First, we define the collision event using offshore jacket installation topology, OSV characteristics, vessel operational conditions and site-specific metocean data. Then, we identify 
key input parameters affecting the collision, namely environmental (such as wind, wave and current) and operational parameters (such as vessel speed and impact location). The probabilistic analysis is carried out to construct a best-fit probability density function (PDF) for each of the parameters. Next, a set of user-defined credible collision scenarios is generated using a statistical sampling technique such as Latin hypercube sampling (LHS) and Monte Carlo simulation (MCS).

In this study, LHS is used because it is more efficient, recreating the input distribution using fewer samples. This generates scenarios by sequential random selection from the stratification of the cumulative probability distribution of input parameters, with one sample chosen per stratification. The number of division is determined depending on the number of the input scenarios required. A series of numerical simulations in a nonlinear time-domain analysis of global ship motions is performed and the load parameters are as follows: collision velocity, angle and location are determined. Subsequently, the statistical characteristics of the load parameters are analysed to assess the best-fit PDF. The goodness-of-fit (GOF) method, using the Anderson-Darling (A-D) test in combination with probability plots for a $95 \%$ confidence interval, is used to verify the compatibility of the selected PDF. The A-D test is a modification of the Kolmogorov-Smirnov (K-S) test that puts more weight on the tails of the distribution (Stephens, 1974). Liu et al. (2016) used LH-moments to estimate the unknown parameters of the probability distribution. In this study, the so called 'minimum COV criterion' (Paik et al., 2004; Paik and Kim, 2012) is used to investigate the effect of the histogram bin width (interval) on the parameters of the distribution. Accordingly, a parametric study of the interval size is conducted to locate the histogram interval that best shows the highest mean and the lowest coefficient of variation (COV) value. In addition, the total number of histogram intervals is calculated using the Doane's formula,

$$
\begin{gathered}
k=\log _{2}(N)+\log _{2}\left(1+\frac{\left|g_{1}\right|}{\sigma_{g_{1}}}\right) \\
\sigma_{g_{1}}=\sqrt{\frac{6(N-2)}{(N+1)(N+3)}}, g_{1}=\frac{\sum(X-\mu)^{3}}{\left[\sum(X-\mu)^{3}\right]^{\frac{3}{2}}}
\end{gathered}
$$

where $X, N$ and $\mu$ represent the sample point, total number and mean of sample points, respectively. Using the aforementioned parameters, the initial kinetic energy $(E)$ imparted to the installation is calculated using the expression (Pedersen and Zhang, 1999),

$$
E=\frac{1}{2} M\left[\left(1+m_{x}\right) \sin ^{2} \alpha+\left(1+m_{y}\right) \cos ^{2} \alpha\right] V^{2}
$$

where $M$ is the mass of supply vessel; $m_{x}$ and $m_{y}$ are surge and sway added masses; $\alpha$ is the collision angle between the ship and installation; and $V$ is the collision velocity of the supply vessel. The added 
mass depends upon the collision parameters, however, in this study the simple approximations are adopted, $m_{x}=1.1$ and $m_{y}=1.4$.

Given the total collision frequency $(\varphi)$, the frequency of exceedance of load parameters is evaluated using (Czujko and Paik, 2015),

$$
R(x)=\varphi \cdot P(X>x)
$$

where $R(x)$ represents monotonically decreasing frequency of exceedance function, which gives the frequency of $X$ being greater than $X$.

Based on the exceedance curve of the load parameters and impact energies, one can select the collision design load parameters based on the designer's acceptable level of risk or on standard design criteria (Youssef and Ince, 2014).

\section{Applied example}

\subsection{Target structures}

The viability of the proposed procedure is demonstrated by using a hypothetical model of an OSV approaching a four-legged offshore jacket platform (see Fig. 5); the particulars are given in Table 2. For simplicity, the considered vessel does not have the DP (dynamic positioning) system and the installation is assumed to be unmanned with no collision avoiding measures beyond those that include a standby vessel, a radar alarming system and a vessel traffic system.

Table 2 Particulars for the target structures

\begin{tabular}{llll}
\hline Principal dimensions & Details & Principal dimensions & Details \\
\hline Jacket structure (4-legged) & & OSV & \\
Height & $148 \mathrm{~m}$ & Overall length & $99.708 \mathrm{~m}$ \\
Freeboard length & $20 \mathrm{~m}$ & Design beam & $23.25 \mathrm{~m}$ \\
Leg Diameter & $2.4 \mathrm{~m}$ & Design draft & $7.1 \mathrm{~m}$ \\
Brace Diameter & $1 \mathrm{~m}$ & Displacement & $8546 \mathrm{tons}$ \\
& & Radius of Gyration, $K_{X X}$ & $8.16 \mathrm{~m}$ \\
& & Radius of Gyration, $K_{Y Y}$ & $25 \mathrm{~m}$ \\
& & Radius of Gyration, $K_{Z Z}$ & $26 \mathrm{~m}$ \\
\hline
\end{tabular}



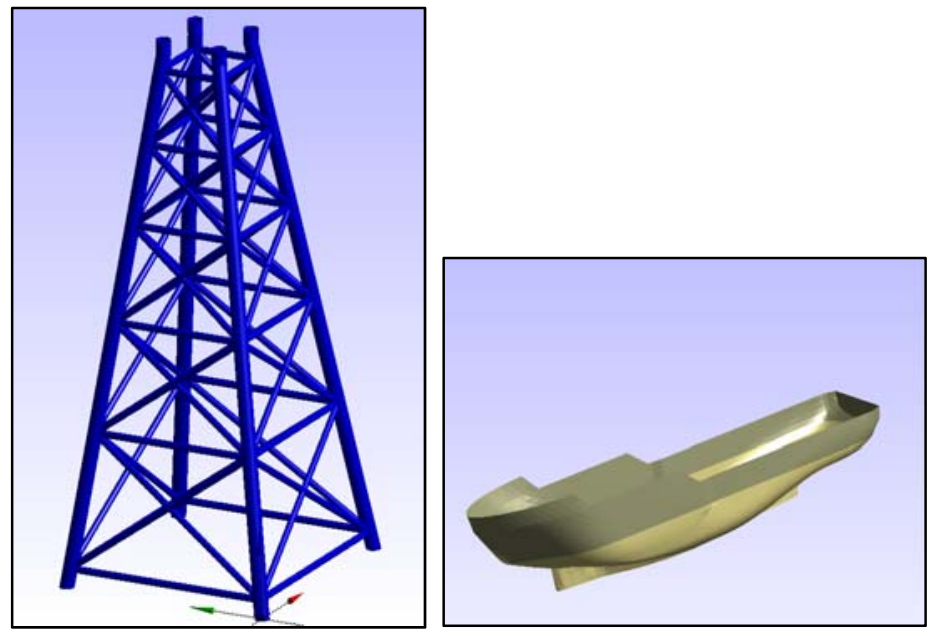

Fig. 5. Target structures (obtained from ANSYS AQWA): offshore jacket platform (left) and OSV (right).

\subsection{Parameters affecting collision scenario}

Various parameters affecting the collision load can be broadly categorised into environmental and vessel operations parameters. In this study, eight environmental and three vessel operational parameters are considered (see Table 3).

Table 3 Description of input collision parameters

\begin{tabular}{lcll}
\hline Type of parameters & Symbol & Random variable & Unit \\
\hline $\begin{array}{l}\text { Environmental } \\
\text { parameters }\end{array}$ & $X_{1}$ & Significant wave height & $\mathrm{m}$ \\
& $X_{2}$ & Zero-crossing wave period & $\mathrm{s}$ \\
& $X_{3}$ & Wave direction & $\mathrm{rad}$ \\
& $X_{4}$ & Wind speed (1-h avg.) & $\mathrm{m} \cdot \mathrm{s}^{-1}$ \\
& $X_{5}$ & Wind direction & $\mathrm{rad}$ \\
& $X_{6}$ & Current velocity (surface) & $\mathrm{m} \cdot \mathrm{s}^{-1}$ \\
& $X_{7}$ & Current direction & $\mathrm{rad}$ \\
& $X_{8}$ & Still water level (SWL) & $\mathrm{m}$ \\
$\begin{array}{l}\text { Vessel operational } \\
\text { parameters }\end{array}$ & $X_{9}$ & Vessel speed & $\mathrm{m} \cdot \mathrm{s}^{-1}$ \\
& $X_{10}$ & Vessel position & $\mathrm{m}$ \\
& $X_{11}$ & Vessel heading & $\mathrm{rad}$ \\
\hline
\end{tabular}

In the absence of real site-specific metocean data, this study considers a hypothetical oceanic region. One can construct a best-fit distribution of each parameter based on the actual collated data by 
following the method described in section 3. Table 4 provides the probabilistic characteristics of the input parameters. The PDF and its environmental parameters are taken from API (2007) and (DNV GL, 2017b). Figure 6 shows various environmental parameters involved in ship-installation collision, where water depth is taken as constant. The still water level (SWL) includes the combined actions of tide and surge. The directions of environmental parameters are defined anti-clockwise from the positive $\mathrm{x}$-axis of the ship's forward motion (i.e., $0^{\circ}$ for astern seas and $180^{\circ}$ for head seas). As vessels approaching close to installations, the same metocean data are also applied for the vessel.

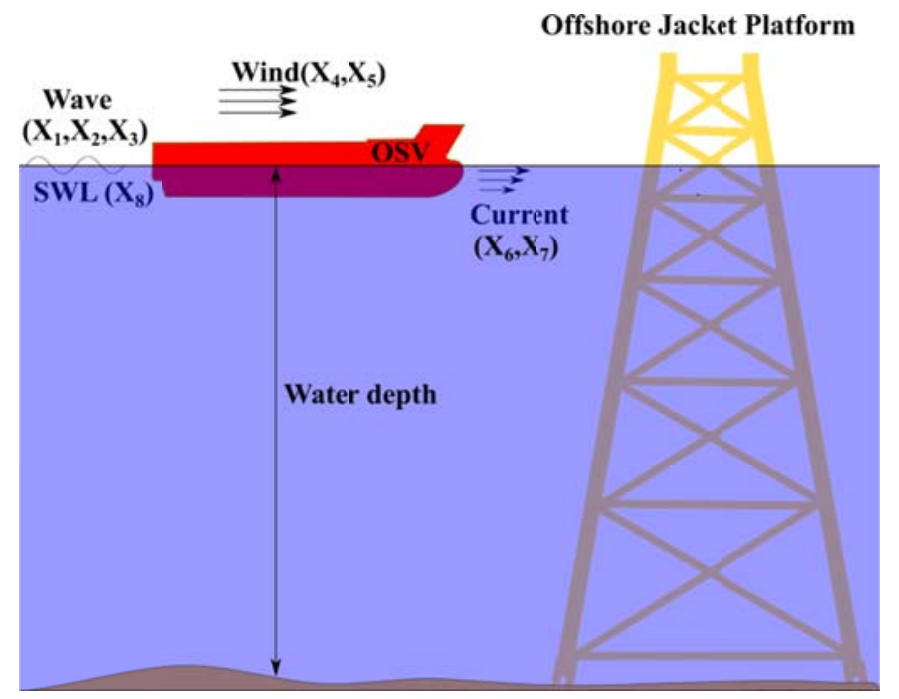

Fig. 6. Representation of environmental parameters involved in OSV-offshore jacket structure collision.

The main factors affecting vessel parameters include the vessel operator's skill and experience, operational procedures, environmental conditions and vessel displacement. Actual historical data of supply vessel operations provide a good estimate of operational parameters. In this study, assumed probability distributions are considered based on operational guidelines and collision geometry. The vessel heading is defined as $0 \mathrm{deg}$ and $180 \mathrm{deg}$ along the port and starboard sides towards bow direction, respectively, and as $90 \mathrm{deg}$. for a head-on collision with a platform. The vessel's course in the $500 \mathrm{~m}$ safety zone can be divided into on-approach, vessel manoeuvring and transfer operations (Spouge, 1999). The majority of attendant vessel collisions occur at low velocities while the vessels are manoeuvring in the vicinity of the installation (Kenny, 1988). Figure 7 shows a schematic diagram of an OSV approaching a platform. The speed of the vessel should be less than $1.5 \mathrm{~m} / \mathrm{s}$ and $0.5 \mathrm{~m} / \mathrm{s}$ inside $200-500 \mathrm{~m}$ and $200 \mathrm{~m}$ radius of the safety zone, respectively. In this study, the approaching vessel's distance to the platform is taken as $200 \mathrm{~m}$, considering the extensive computations required for a more distant ship. Also, the collision probability at a far distance from a platform is marginal, given that more reaction time is available to successfully avert an impending collision (IMECA, 2009). Figure 8 shows the selected PDFs of all the input parameters. 
Other vessel parameters such as vessel mass, type and geometry are taken as a constant, due to the fact that the same vessel generally visits an installation based on the platform requirements, geographical location and type of the installation, among other considerations. The vessel draft is also taken as constant, with vessels approaching the installation with full ballast (Aas et al., 2007). The effects of possible waves from passing vessels are ignored in this study.

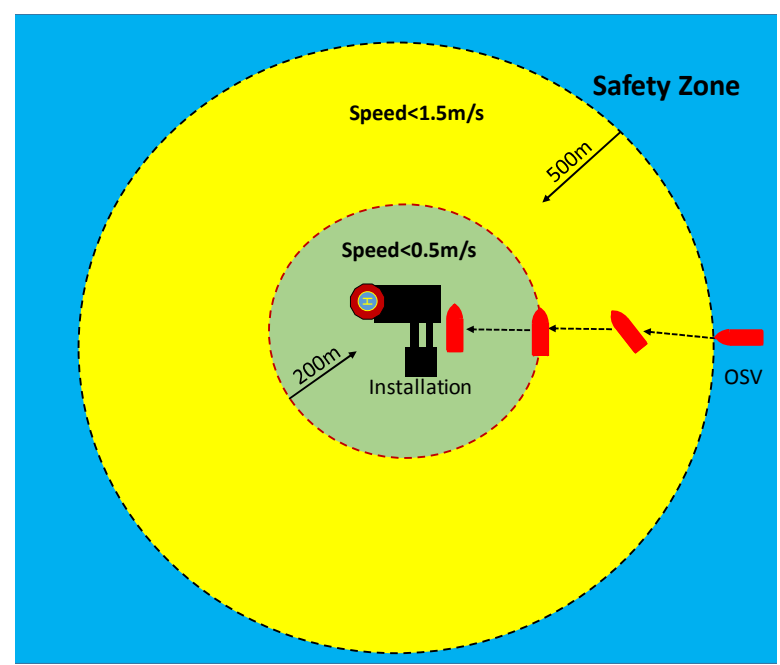

Fig. 7. Schematic view of an OSV approaching to an offshore installation, showing its speed and course inside 500m safety zone \{adopted from (Step Change in Safety, 2017)\}.

Table 4 Probabilistic characteristics of input parameters

\begin{tabular}{llll}
\hline $\begin{array}{l}\text { Random } \\
\text { variable }\end{array}$ & Distribution & Parameters & Reference \\
\hline$X_{1}$ & Weibull & $\alpha=1.81, \beta=1.47$ & (DNV GL, 2017b) \\
$X_{2}$ & Lognormal & $\begin{array}{l}\mu=0.7+0.95 H_{s}^{0.158}, \\
\sigma=0.07+0.1685 e^{\left(-0.0312 H_{s}\right)}\end{array}$ & (DNV GL, 2017b) \\
& & $s=5$ & (DNV GL, 2017b) \\
$X_{3}$ & Directional function & $\alpha=0.61, \beta=0.725$ & (API, 2007) \\
$X_{4}$ & Lognormal & $s=5$ & (DNV GL, 2017b) \\
$X_{5}$ & Directional function & $\mu=-1.1187, \sigma=3.432$ & (API, 2007) \\
$X_{6}$ & Lognormal & $s=5$ & (DNV GL, 2017b) \\
$X_{7}$ & Directional function & $\mu=0.984, \sigma=3.245$ & (API, 2007) \\
$X_{8}$ & Weibull & $\mu=-0.5102, \sigma=0.5214$ & Assumed \\
$X_{9}$ & Lognormal & $\mu=1.67, \sigma=0.82$ & Assumed \\
$X_{10}$ & Lognormal & $\mu=0.5, \sigma=0.785$ & Assumed \\
$X_{11}$ & Normal & & \\
\hline & & $s$ & \\
\hline
\end{tabular}



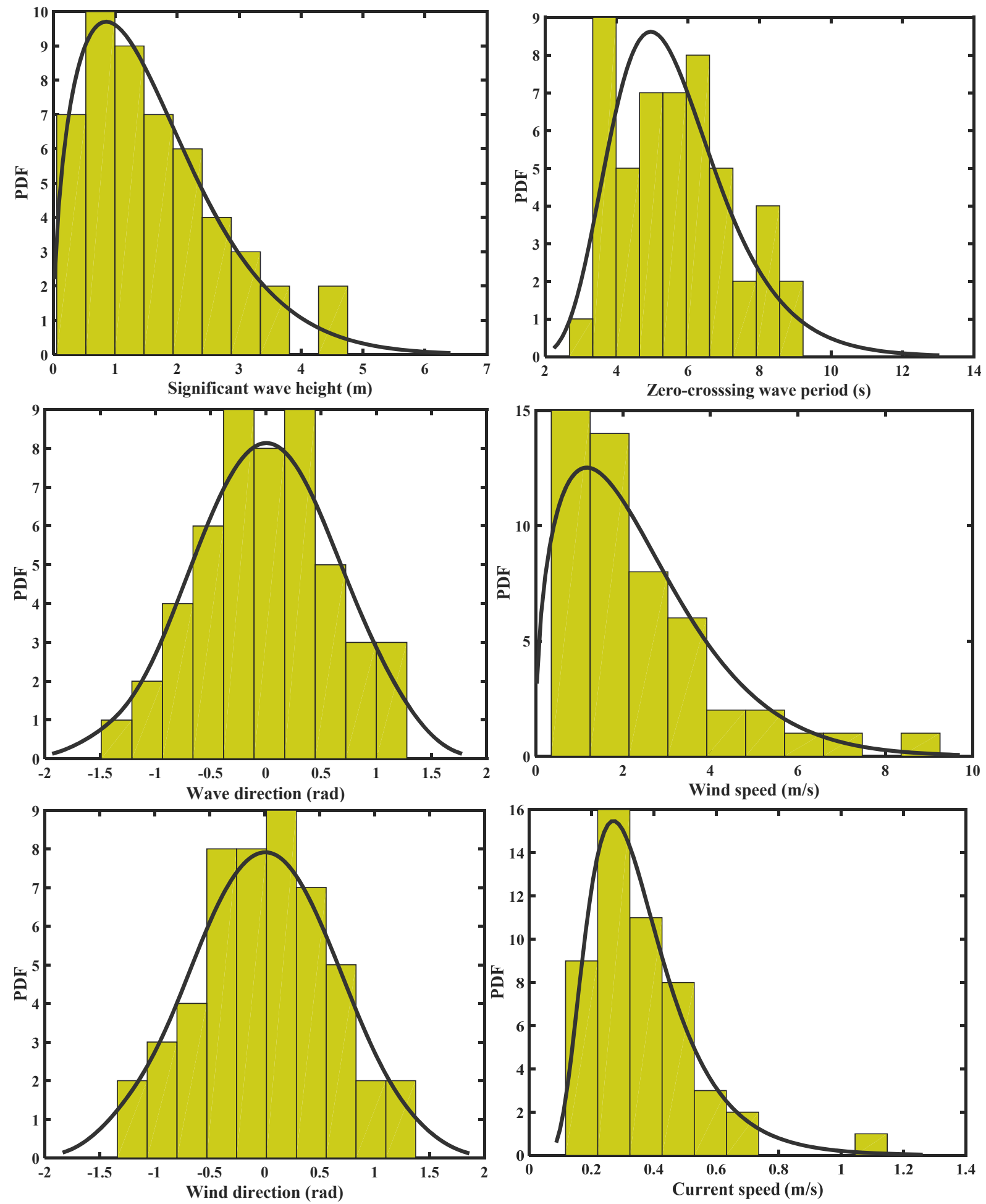

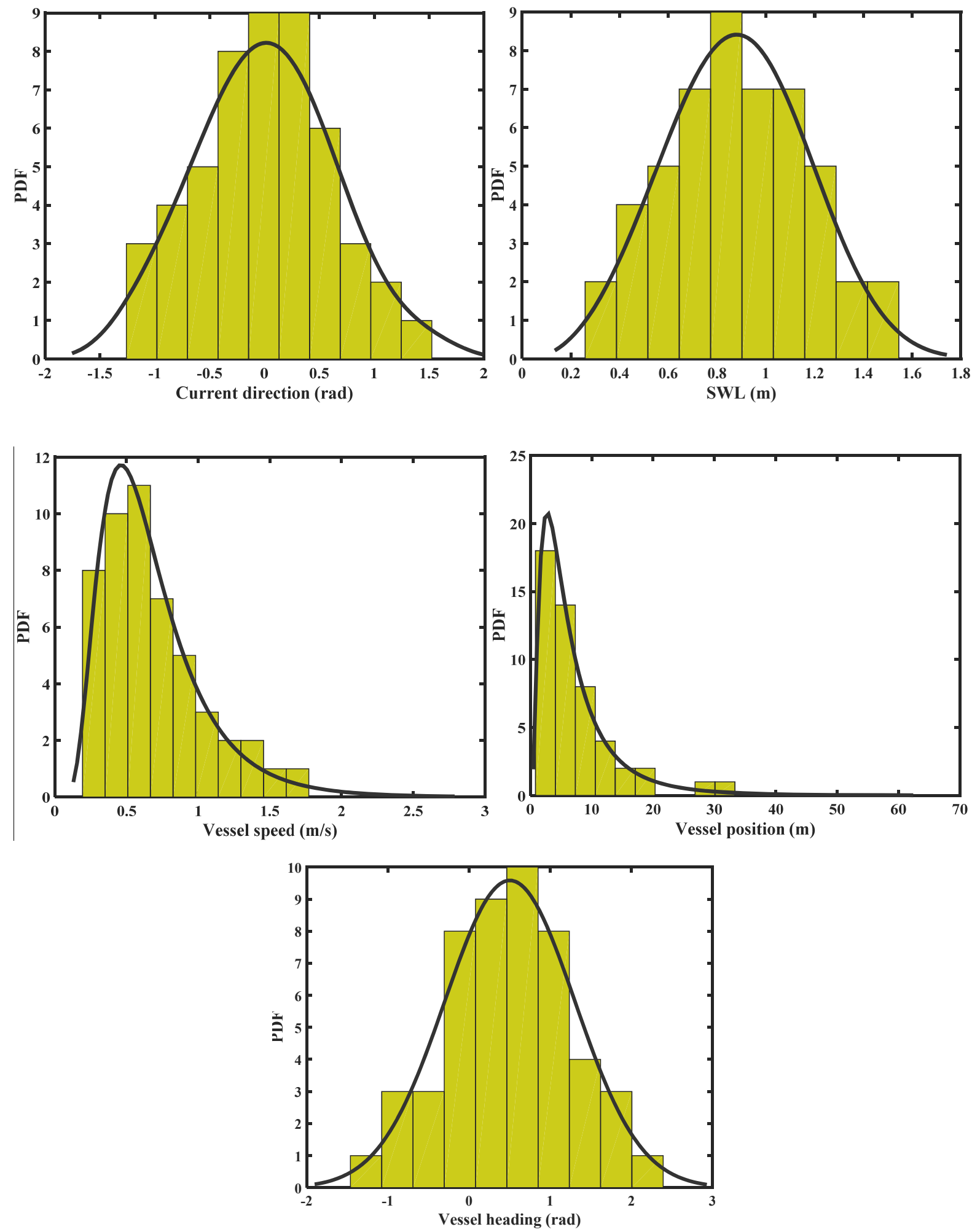

Fig. 8. Selected PDFs of environmental and vessel operational parameters. 


\subsection{Numerical simulation}

ANSYS AQWA software is used to simulate real-time ship motions to an installation. The simulation is based on potential theory and uses a three-dimensional panel method to model the vessel. First, the equation of motions is solved in the frequency-domain using the AQWA-LINE module, followed by the nonlinear time-domain analysis of ship motions in AQWA-NAUT. At each time step, a two-stage predictor-corrector method is used to get the time history velocities and positions of ship motions by integrating acceleration due to the forces of wind, waves and currents.

The input wave frequencies and directions range from 0.0159 to $0.245 \mathrm{~Hz}$ (20 frequency intervals) and from -180 to +180 degrees (45-degree interval), respectively. The Pierson Moskowitz (P-M) spectrum is used to define the constant of irregular waves. Constant wind speed and current are considered during the simulation. For simplicity, initial rotational velocities and fluid-structure interaction are disregarded; the centre of gravity of the ship is located on the centre line amidships. Using Table A.1, a series of time-domain simulations of ship motions is performed. Figure 9 shows an example of the time history of ship velocities, heave, pitch and yaw angle corresponding to scenario-5, where the vessel is in contact with the installation at time $t=270.8 \mathrm{~s}$.

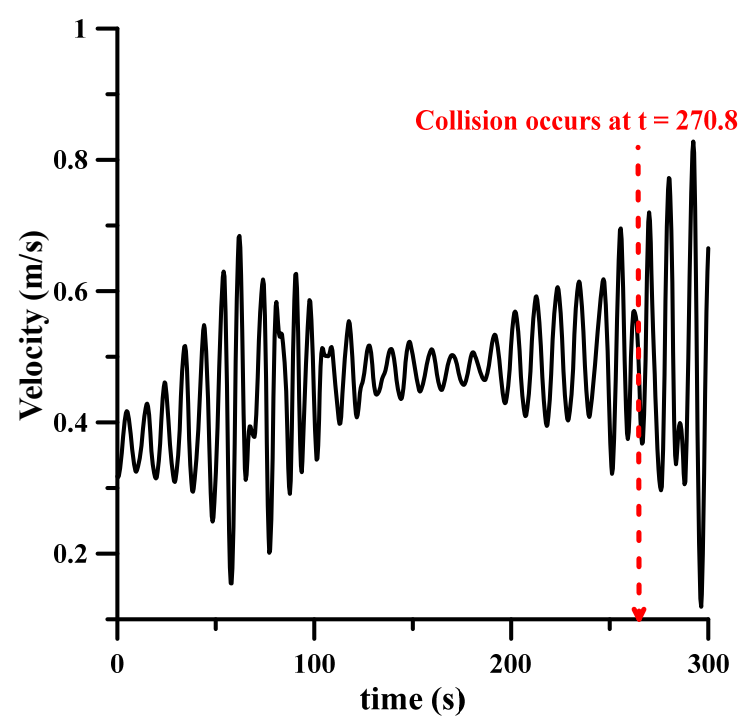

(a)

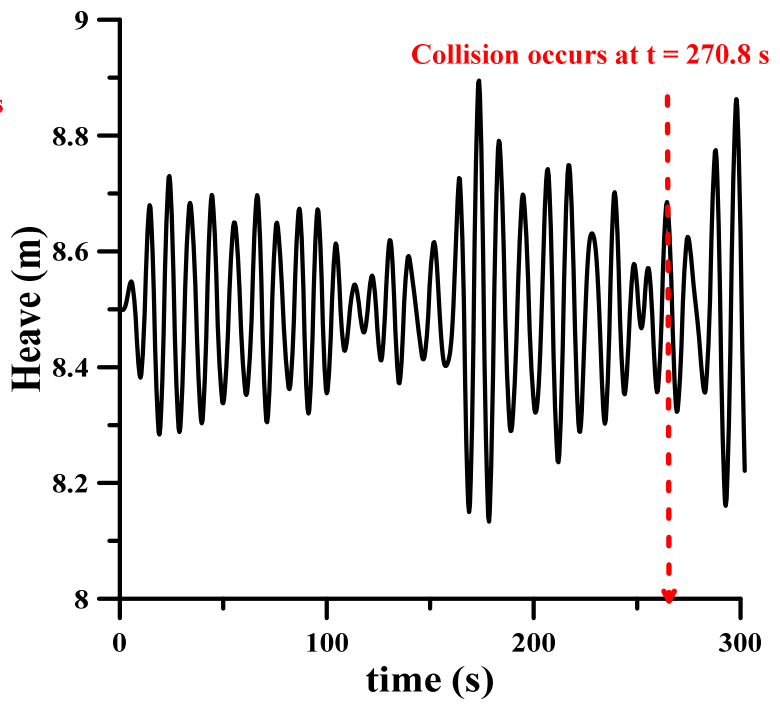

(b) 


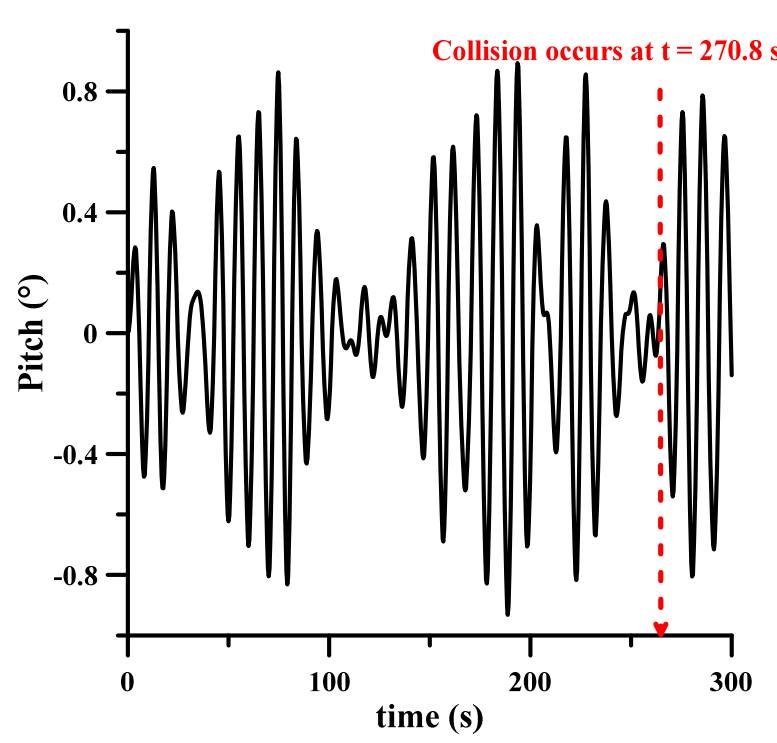

(c)

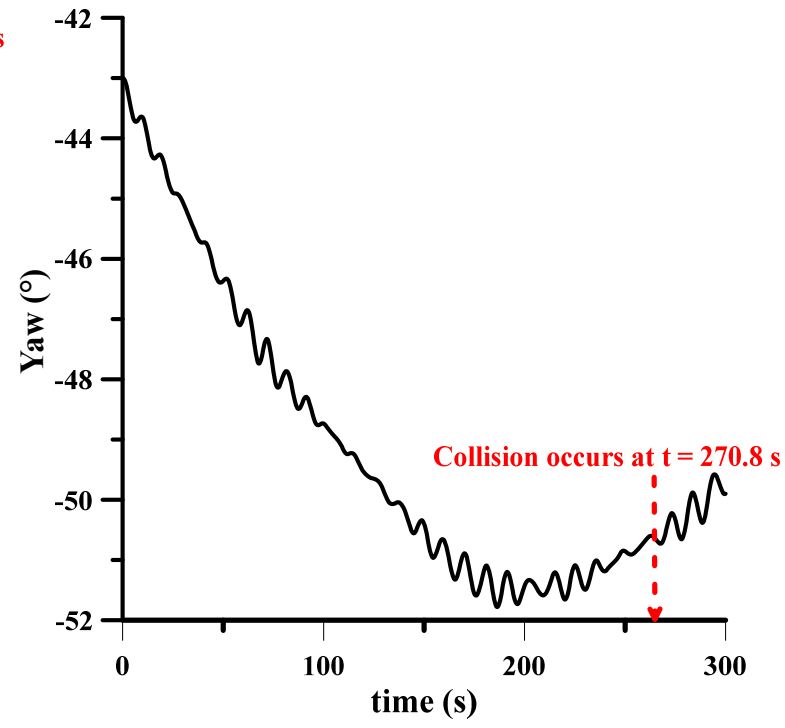

(d)

Fig. 9. An example of time history of ship motions (scenario-5): (a) velocity, (b) heave, (c) pitch and (d) yaw.

The ship-installation collision geometry can be modelled using the mass of the ship (including hydrodynamic added mass), velocity, collision angle and location at the instant of impact (Deeb et al., 2017; Wang et al., 2006; Zhang et al., 2015). In this study, four load parameters are considered: collision velocity $(V)$, impact angle $(\theta)$, horizontal impact location $(r)$ and vertical impact location (l). The angle represents the yaw motion of the ship with respect to jacket structure (see Fig. 10 for geometric definition). All of the parameters represent the exact moment when the ship touches the installation's leg or braces.

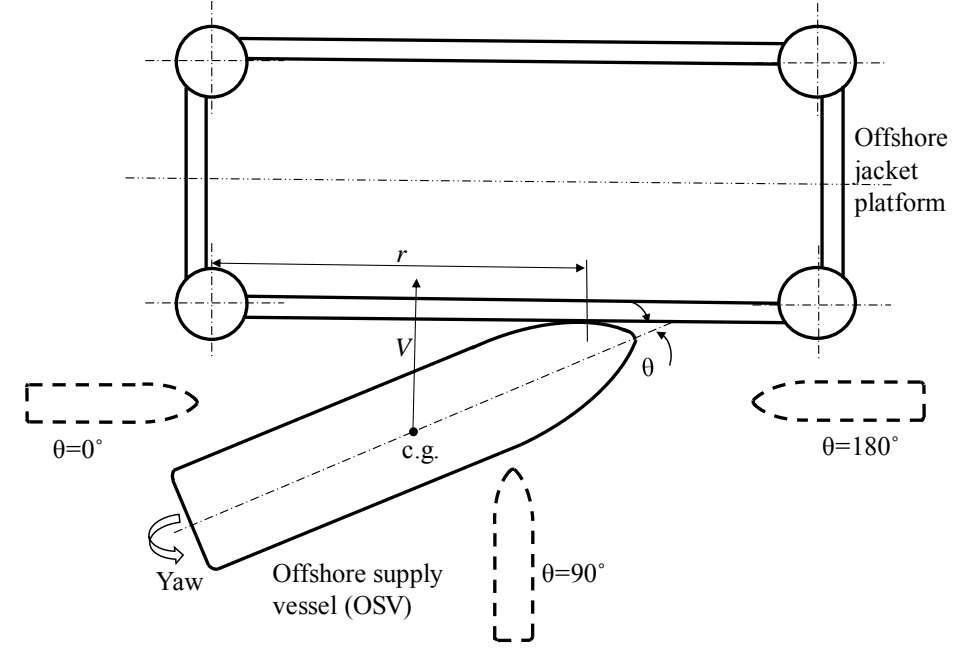

Fig. 10. Simplified 2D model of an OSV-offshore installation collision. 


\section{Results and discussion}

\subsection{Probabilistic selection of collision scenarios}

The LHS sampling technique was used to generate a set of 50 collision scenarios using the PDFs of input parameters (see Table A.1). Figure 11 shows a summary of the selected values of all the input parameters in the form of a scatter diagram. The diagonal elements display the histogram of each parameter and the off-diagonal elements shows the correlation between two parameters.

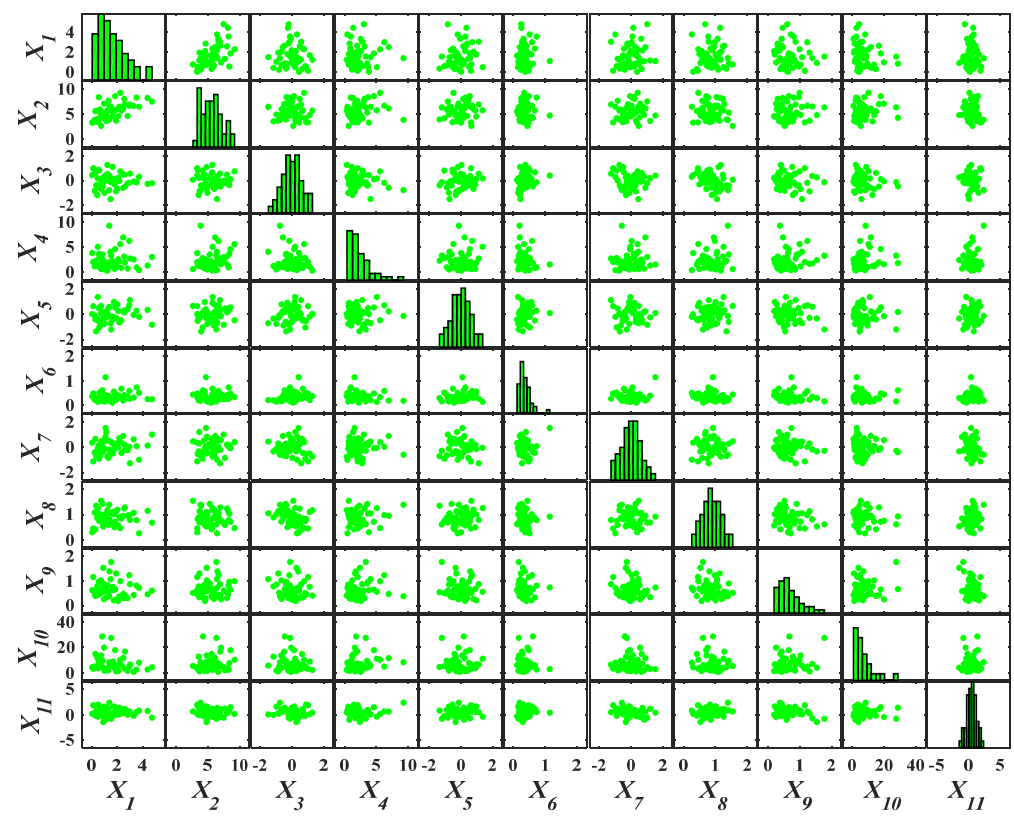

Fig. 11. Scatter plot of input parameters.

Table 5 shows the summary of the fifty collision scenarios based on the simulation results. It is observed that the maximum velocity is $1.65 \mathrm{~m} / \mathrm{s}$, which is less than the design velocity of $2 \mathrm{~m} / \mathrm{s}$, conforming to the lower vessel manoeuvring speed inside the safety zone. The vertical impact location falls within the limits of the NORSOK (2007) guidelines (i.e., -10 to $13 \mathrm{~m}$ ), except for scenarios 5, 10, 42 and 46. The total horizontal impact zone was calculated using the 'collision diameter' defined by Spouge (1999), which is the summation of platform width at the waterline section $(38.2 \mathrm{~m})$ and the vessel breadth $(23.25 \mathrm{~m})$. Vinnem (2014) classified collison into glancing, corner column and bracing, with the conditional probabilities of the collison scenarios defined by $20 \%$, $60 \%$ and $20 \%$ of the total impact zone, respectively. Figure 12 shows the number of collisons occurring at each of these locations. It can be seen that frequency of a jacket bracing collision is almost $50 \%$ higher than the frequency of a glancing or corner column collision, which demands greater care in the design stage. 
Tab

\begin{tabular}{lll}
\hline Scenario & $V(\mathrm{~m} / \mathrm{s})$ & $\theta(\mathrm{deg})$ \\
\hline 1 & 0.36 & 65.69 \\
2 & 0.68 & 10.29 \\
3 & 0.57 & 54.12 \\
4 & 0.35 & 4.32 \\
5 & 0.75 & 50.46 \\
6 & 0.26 & 108.88 \\
7 & 0.32 & 16.61 \\
8 & 0.74 & 23.25 \\
9 & 0.68 & 64.14 \\
10 & 0.23 & 127.45 \\
11 & 1.65 & 107.73 \\
12 & 0.70 & 53.65 \\
13 & 0.42 & 77.37 \\
14 & 0.70 & 57.49 \\
15 & 0.40 & 42.73 \\
16 & 0.26 & 77.40 \\
17 & 0.42 & 158.72 \\
18 & 0.22 & 123.65 \\
19 & 1.39 & 66.42 \\
20 & 0.65 & 68.41 \\
21 & 0.43 & 125.13 \\
22 & 0.66 & 25.82 \\
23 & 0.40 & 50.04 \\
24 & 0.15 & 110.04 \\
25 & 0.37 & 90.00 \\
\hline
\end{tabular}

25

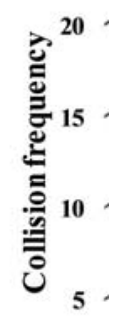

o

Fig. 12. Frequen 